\title{
Relating is an Operant: A Fly Over of 35 Years of RFT Research*
}

Relacionar é um operante: um sobrevôo nos 35 anos de pesquisa sobre RFT

\author{
Relacionar es una operante: un vuelo sobre 35 años de investigación \\ en TMR
}

Steven C. Hayes ${ }^{1}$, Stu Law', Kian Assemi', Neal Falletta-Cowden ${ }^{1}$, Melia Shamblin ${ }^{1}$, Kenneth Burleigh ${ }^{1}$, Rita Olla $^{1}$, Michelle Forman', and Patrick Smith ${ }^{1}$

\begin{abstract}
Relational Frame Theory (RFT) is the simplest form of operant theory since it claims nothing more than a particular type of behavior, arbitrarily applicable derived relational responding, is an operant. While the theory is simple, its implications are not, and adoption has been slow until recently. RFT was first formally described in 1985 and in the 35 years since, hundreds of studies have been conducted on relational learning from an operant point of view. The present paper briefly summarizes that history and examines some of its key claims. So far, the empirical program delineated by RFT has held up remarkably well. Future directions are delineated that will enable a more comprehensive evaluation of the importance of the RFT research program, and a more thorough exploration of its profound implications.
\end{abstract}

Keywords: relational frame theory; stimulus equivalence; relational operants; verbal behavior; human language; symbolic behavior; transformation of stimulus functions; mutual entailment; combinatorial entailment

*This manuscript was originally published in Portuguese as a chapter of the book "Relational Frame Theory (RFT): Concepts, Research, and Application" (Perez, Kovac, de Almeida, \& de Rose, in press). 
Resumo: A Teoria das Molduras Relacionais (RFT) é a forma mais simples de teoria operante, uma vez que afirma que um tipo particular de comportamento, a resposta relacional derivada arbitrariamente aplicável, é um operante e nada mais do que isso. Embora a teoria seja simples, suas implicações não são, e a adoção tem sido lenta até recentemente. A RFT foi descrita formalmente pela primeira vez em 1985 e, nos 35 anos desde então, centenas de estudos foram conduzidos sobre a aprendizagem relacional de um ponto de vista operante. O presente artigo resume brevemente essa história e examina algumas de suas reivindicações principais. Até agora, o programa empírico delineado pela RFT se manteve muito bem. Algumas direções futuras são delineadas que permitirão uma avaliação mais abrangente da importância do programa de pesquisa da RFT e uma exploração mais completa de suas profundas implicações.

Palavras-chave: teoria das molduras relacionais; equivalência de estímulos; operantes relacionais; comportamento verbal; linguagem humana; comportamento simbólico; transformação de funções de estímulo; implicação mútua; implicação combinatória

Resumen: La Teoría de los Marcos Relacionales (TMR) es la forma más simple de teoría operante al mantener que un tipo particular de conducta, el responder relacional derivado arbitrariamente aplicable, es una operante. Mientras que la teoría es simple, sus implicaciones no lo son, y su adopción ha sido lenta hasta hace poco. La TMR fue descrita por primera vez formalmente en 1985 y en los 35 años que han pasado desde entonces se han conducido cientos de estudios sobre aprendizaje relacional desde una perspectiva operante. El presente artículo resume brevemente esa historia y examina algunas de sus afirmaciones fundamentales. Hasta ahora, el programa empírico delineado por TMR se ha mantenido notablemente bien. Se delinean las direcciones futuras que permitirán una evaluación más completa de la importancia del programa de investigación en TMR y una exploración más profunda de sus profundas implicaciones.

Palabras clave: teoria del marco relacional; equivalencia de stimulus; operantes relacionales, conducta verbal, lenguaje humana, conducta simbólica, transformación de funciones, vinculación mutual; vinculación combinatorial 
Relational Frame Theory (RFT; Hayes, BarnesHolmes, \& Roche, 2001) presents as a paradox. It is perhaps the simplest behavioral theory ever created, since it can be adequately stated in five words: verbal events are relational operants. If applied studies based on RFT ideas are included, there are likely more experimental studies on RFT across a wider range of topic areas than any other behavioral approach to language and cognition. The core idea of RFT is nearly 40 years old and a formal program of RFT research and theorizing is about 35 years old. The consistency and empirical progressivity of RFT research findings is clear and unusual.

Despite its parsimony, age, depth of empirical examination, and consistency of empirical support, RFT is still not viewed as an essential part of behavior analysis. Board Certified Behavior Analysts do not have relational framing per se on their task list. Intervention methods based on Acceptance and Commitment Therapy (ACT; Hayes, Strosahl, \& Wilson, 2012) or any other applied extension of RFT are not there either. Many behavior analytic articles on verbal behavior or even on derived relational responding fail to mention obvious RFT connections. In many circles of the field of behavior analysis that deal with human language and cognition, RFT is simply ignored.

While that is beginning to change-as is shown by this very book ${ }^{1}$-there are two important reasons for this slow adoption. The first is that while the idea of purely functional operants has been part of behavior analysis from the beginning, the field has never become entirely comfortable with that fact nor very clear about its implications. The second is that it is an empirical fact - as much as anything is a fact in behavior analysis - that relational operants operate on stimulus functions that are established by direct contingencies. Said in another way, we know that this evolutionarily recent human operant learning process interacts with learning processes that may be a thousand times older.

These two features matter. They upend mechanistic ideas in behavioral psychology, and they demand that human research per se must receive proper attention in basic behavior analysis. Together they

1 "Relational Frame Theory (RFT): Concepts, Research, and Application" (Perez, Kovac, de Almeida, \& de Rose, in press). suggest that if the field of behavior analysis cares about human behavior, it cannot be satisfied with principles derived from non-human animals alone.

In this chapter we will consider the nature of purely functional operants, touching on learned variability, learned novelty, learned randomness, and imitation as an operant. We will briefly examine the empirical RFT literature in a small set of areas relevant to a simple claim: relational operants exist and can help in the analysis of complex human behavior.

\section{The Operant Unit and Functional Classes}

Anecdotally, it seems that functional analytic thinking is unnatural to many. Within our presumed-common history we do not often encounter sciences that study, as their fundamental unit, the interactions of things with other things. Psychology is the study of single, whole, organisms and their interactions with environing conditions, considered both historically and situationally. It is a subject matter that is sometimes tricky to conceptualize. While a physicist may be said to be studying the properties of matter, and a chemist may be said to be studying chemical compositions-a psychologist has a base scientific unit that is an impermanent, fleeting, and ever-evolving interaction which only occurs at the level of the individual organism.

Given our extended histories with other natural sciences, it is understandable that we may begin to interpret behavior in terms of mechanistic forces and objects as we use familiar metaphorical extensions to describe events as we see them. It is easy to fall into that deeply rich and temporally extended history of understanding science in terms of these other subject matters. As such, the study of complex human behavior has been plagued with homunculi, invisible transcendental forces, nominal fallacies, and reified constructs (Kantor, 1963). Non-observable, nonnaturalistic ideas still plague psychology - indeed they have been made more difficult to eliminate by the sleight of hand of claiming that bodily systems (especially neurons) make up these invisible forces. Unfortunately, treating spooks as meat does not make them less spooky in a functional sense. 
Our history with the predominance of mechanistic sciences interferes with our ability to see behavior as a natural phenomenon. Behaviorists themselves have struggled in their own way with this issue. The 'bottom-up' approach of creating explanatory constructs for direct-contingency and animal learning has led to stretched, and imprecise ideas which have largely inadequately dealt with major areas of complex human behavior. It is understandable that a science of human behavior is difficult. Challenges abound on the way to a naturalistic account of the expansive repertoires of humankind.

As an initial challenge, let us consider 'the operant' as a unit of analysis. Operants are composed of an antecedent stimulus (often denoted ' $S$ '), a response (R), and a consequating stimulus (S). The operant unit of behavior is thus, typically represented as $S-R-S$. However, over time a new initialism emerged- "A-B-C". Here, the operant is slightly recast as an "Antecedent". "Behavior". "Consequence". $A-B-C$ is not without its virtues. It is catchy and easy to remember. The terms 'antecedent' and 'consequence' are more descriptive than the general term 'stimulus' for the states of affairs that prevailed before and after a transition.

However, $A-B-C$ does contain at least one significant problem when teaching the analysis of behavior. It lands as a sequence of units - not a single unit. That idea conflicts with operants as Skinner understood them, since operant behavior is a single three-term S-R-S unit (or a similar four-term interaction if motivational operations are to be added to the definition of operants).

This may sound like a picky and unnecessary distinction, but the understanding of behavior as an ever-evolving interaction between an organism and its environment is lost when "behavior" is reduced to the actions of muscles, glands, and living tissue and then that discrete unit is glued into a sequence of discrete events. It is vital for operant psychology to keep its unit whole if we are to avoid the reification, nominalization, and mechanistic interpretations of behavior that has led psychology into nonnaturalistic cul de sacs so often.

The oft-cited 'dead man test' for behavior, is misleading in this same way. Within an effective science of behavior actions in isolation are not mean- ingful units of analysis unto themselves. Without the interaction of the organism and the environment found in the S-R-S unit, behavioral functions that are unified by their common antecedent and consequential conditions are easily lost.

When behavior analysts think of 'behavior' as the ' $\mathrm{B}$ ' in the middle of the operant unit, it is easy to take a small additional step and adopt the idea that behavioral classes are collections of topographies. While topographical classes of behavior are not entirely unimportant (e.g., to a coach trying to teach someone how to hit a golf ball) the idea interferes with the flexibility needed to think about the world in ways that inform human functioning while maintaining contact with the evolutionary metaphors of variation, selection, and retention that may help us create a more adequate science of human behavior.

Consider the phenomenon of generalized imitation (Baer, Peterson, \& Sherman, 1967; Gewirtz \& Stingle, 1968). The purpose of shaping a broadly applicable imitation repertoire is to establish a pattern of having the learner 'do as the model does'a repertoire which is tremendously useful for the foundations of learning verbal behavior. When sufficiently mastered, the learner should, by definition, be able to imitate a near-infinite number of sounds, postures, movements, and actions-each of which can be said to be serving within the same functional class. When we target imitative repertoires, we are not simply seeking to shape, "smiling", "waving", "pointing", etc. as behaviors-we are slowly building the functional response class: 'do something that looks like what the model is doing when a set of antecedent conditions are present, and something at least somewhat predictably pleasant will happen.' No amount of topographical specification can characterize such a radically functional class of actions.

Some functional classes may actually be defined by a distinct absence of topographical similarity. For example, Karen Pryor and colleagues were able to successfully shape repertoires in animals which may be described as "do something I have never seen you do" (Pryor, Haag, \& O’Reilly, 1969). Upon interacting with a discriminative stimulus that sets the occasion to "do something new" porpoises can reliably demonstrate learned novelty as an operant class. Such an operant, such an S-R-S unit, contains 
a response that is, by definition, not bound to any topographical form-yet clearly remains a commonsense class of responding which can be taught. Human beings can learn to emit numbers in truly random order (Neuringer, 1986), and rats can learn to interact variably with objects in ways that later lead to more rapid solutions when confronted with novel problem-solving tasks (Weiss \& Neuringer, 2012). The deeply important lesson is that operants are not necessarily defined by topographies at all - they are functional relations that sometimes include particular topographies if and when that very property is itself functional.

Part of what appeared to be so revolutionary about Skinner's Verbal Behavior (1957) was that it conveyed for the first time a consistently functional account of why we communicate. This functional approach still stands out as exceptional as many other fields of language which are composed of more nominalized interpretations, focusing on somewhat concrete units such as 'grammar', 'language', and dictionary 'definitions' only found at the level of broad verbal communities. Mands, tacts, intraverbals, autoclitics, and the like are all defined by the events which occur before and after the response of interest. They are classifications of operants regarding 'why' we speak. The form of the response is seldom important, and even often misleading. Any utterance or action whose reinforcement is mediated through a listener trained to do so could be any one of a number of verbal events, depending upon the conditions surrounding the controlling functions. For example, a spouse may recognize his wife's raised eyebrow as an oft reinforced mand for more coffee. It is a verbal episode in the Skinnerian sense.

As an example of how this functional approach may be useful: suppose that a behavior analyst is consulting with a teacher who is attempting to teach a child to mand for access to the bathroom. The behavior analyst may observe that when the student says, "toilet please!" in the classroom, the student nearly never attempts to go to the bathroom. The student, instead, subsequently spends 5 minutes pacing around the classroom disrupting other students until the teacher's patience wanes and the student is invasively prompted to sit back down in their seat. What may be clear is that the be- havior analyst is seeing that the function of the student saying the words "toilet please" is in fact a kind of mand which makes access to other students and areas of the classroom easier-and which makes the teacher more likely to be temporarily lenient with regard to disruptive behavior. Though the teacher, and perhaps a whole host of expert educators and practitioners may report that they are teaching the student to use the bathroom more effectively, the antecedent conditions that evoke the response are actually the absence of interesting activity, not the sensation of needing to go to the bathroom. Likewise, the reinforcing consequence may have nothing to do with access to the bathroom to relieve the pressure of built-up waste. The teacher may have been better off teaching the learner to say, "let me wander around for a few minutes please!" as that is a more apt description of the functional contingencies at play here. Those not trained to observe behavioral functions are often fooled by responsetopographical sleight-of-hand such as this - saying 'toilet please' is topographically a fine response and seemingly well worth training - but this hypothetical intervention is unlikely to be of any use to anyone. Skinner's analysis Verbal Behavior helps orient us to the raw functional causes behind these kinds of responses and helps us teach some foundational language skills where others fail.

What had long been missing from the analysis of human behavior was a theory that provided that same raw, functional account, to communicative events. B. F. Skinner wrote Verbal Behavior more than 60 years ago and he was formulating its contents 70 years ago. It was a major step forward in many ways, but it was limited by what was known at the time. Skinner himself viewed it as an exercise in interpretation, and although it has generated a body of research, three properties in particular have proven impossible to overcome in the attempt to use his theory as a foundation for work with verbally able humans. The first was that the behavior of the listener was not itself verbal and thus it was difficult to extend the analysis to rule-governance, understanding, and similar topics. Second, the identification of verbal behavior as a functional class required an analysis of the history of the listener (namely the training history needed to teach the listener to mediate reinforcement to the speaker) 
thus moving the operant unit from the psychological to the sociological level. And third, the definition was broad enough so to include the actions of non-human animals in programmed operant experiments, and thus as a basic matter there was no fundamental need to study verbal behavior in its own terms and with human beings.

This was the state of affairs when RFT was developed in 1982 or 1983 by a unified lab team composed of a young faculty member who was a behavior analytically oriented clinical psychologist (the first author of this paper, $\mathrm{SCH}$ ) and a well-known senior basic behavior analyst who published basic studies conducted with non-human animals (Aaron Brownstein). For the clinical work then underway in that lab an analysis was needed that was empirical, not just interpretive; that treated listeners as verbal and thus could make sense of such phenomena as rule-governed behavior or human schedule control; that was functional entirely at the psychological level; and that began to make basic and applied sense of what is characteristically human in the area of language and higher cognition. It was Brownstein who first suggested that the then quite new phenomenon of stimulus equivalence could form a possible way forward. At the time "stimulus equivalence" was entirely an outcome finding, but it has already begun to raise hopes among some behavior analysts that all of the above features could be solved by it. All, that is, except one: a functional account. That was not yet possible since it was merely an outcome finding at the time.

$\mathrm{SCH}$ proposed that functional account about a week later. It was the simple possible explanation an operant psychologist could provide: relating is an operant. Aaron Brownstein approved of the radically functional nature of that answer and within days the theory had taken shape and about 25 possible empirical studies had been outlined with findings that had to be the case if this theory was correct (that list of future studies appears to have been lost to history but most of them had been checked off as successfully completed by the early 2000's, when it appears the list is permanently misplaced during a move).

By Spring 1985 the Hayes and Brownstein team were finally ready to present Relational Frame Theory to the world of behavior analysis at the an- nual conference of the Association for Behavior Analysis. In that talk, relational framing was used to redefine verbal behavior as "speaking with meaning and listening with understanding" based on whether actions of the speaker or listener were based on relational operants. Less than a year later, Aaron Brownstein died while dancing with his wife, and while his name is on many key articles from this developmental period (e.g., Hayes \& Brownstein, 1986; Hayes, Brownstein, Devany, Kohlenberg, \& Shelby, 1987; Hayes, Brownstein, Haas, \& Greenway, 1986; Hayes, Brownstein, Zettle, Rosenfarb, \& Korn, 1986) he was not able to be on the key articles that otherwise would have forever defined him as the cocreator of RFT - which he in fact was.

\section{Equivalence and 'Equivalencing'}

Beginning as a fairly humble attempt to teach an institutionalized 17-year-old boy to read (Sidman, 1971), Murray Sidman found an important thread for behavior analytic thinkers to pull-equivalence relations. This outcome is said to occur when a stimulus, as an example we may say the written word DOG (A), with a pictorial representation of a $\operatorname{dog}(\mathrm{B})$. Given a stimulus (such as the word DOG) the person will pick it from an array. That is what later would be called "reflexivity." When the learner reliably selects $B$ in the presence of $A$, that the $B$ stimulus (in our case the picture of a dog) is trained to be selected from an array upon hearing the spoken word "dog" (C). What excited Sidman and fellow researchers was that in the case of this institutionalized boy, and in many cases that followed, when the A-B relationship was trained, trials presenting $B$ led to the selection of $A$. The inverse, though not directly trained, was successfully demonstrated. As can be imagined, a similar thing occurred when B-C was trained; the $\mathrm{C}$ to $\mathrm{B}$ training was 'free' in the sense that it emerged on the first trial with no prior direct training. In addition to these 'free' (what Sidman would later call "symmetrical") responses, the participant was able to derive the relationship between $\mathrm{A}-\mathrm{C} / \mathrm{C}-\mathrm{A}$ and say the word "dog" when presented with the printed word DOG even though, prior to his first successful trial, those two stimuli had not been associated 
through any kind of direct training or reinforcement. Success in selecting $A$ in the presence of $C$ is now known amongst those who study the phenomenon as an 'equivalence relation'.

The implications of this free, not-directlytaught, learning outcome loomed large for Sidman who recognized early on that it might form the basis of semantic meaning (Sidman, 1994). For that claim to be fully viable a theory would be needed, but for more than a decade Sidman himself was content to try to define the features of the phenomenon precisely, relying heavily on set theory to do so (e.g., Sidman, 1994; Sidman \& Tailby, 1982). The defining features of equivalence relations - reflexivity, symmetry, and transitivity - were very helpful because they defined stimulus equivalence with sufficient precision that an empirical foundation could be established.

In the 1980s Sidman himself found that nonhuman animals did not form equivalence classes (Sidman et al., 1982); equivalence could be used to teach developmentally disabled persons (Mackay, \& Sidman, 1984); very large classes could be formed with a staggering number of derived stimulus relations (Sidman, Kirk, \& Willson-Morris, 1985); equivalence could come under contextual control (Bush, Sidman, \& de Rose, 1989); and common names were not necessary for the emergence of equivalence (Sidman, Willson-Morris, \& Kirk, 1986). But Sidman recognized that he did not have a theory of how equivalence came to be, however - what he had was a definition of the phenomenon to be explained.

RFT and the Hayes/Brownstein lab entered the picture immediately after Sidman and Tailby's article in 1982 and before Sidman's theoretical account had begun to form. In the next decade the lab showed that children who did not show stimulus equivalence did not develop normal receptive language (Devany, Hayes, \& Nelson, 1986); that verbal rules altered contingency shaped performances (Hayes \& Brownstein, 1986; Hayes et al., 1986); that the absence of verbal control in protocol analysis tasks could be used to infer the presence of selfrules (Hayes, 1986); that in order for the impact of self-rules to be understood non-mentalistically, the demonstration of contextual control was essential (Hayes \& Brownstein, 1986); that the transforma- tion of stimulus functions was a fundamental and defining feature of equivalence classes and other forms of derived relational responding (Hayes et al., 1987; Wulfert \& Hayes, 1988) and thus that derived relational responding could help explain rule-governed behavior (Hayes, Thompson, \& Hayes, 1989); that any kind of stimulus could enter these relations (Hayes, Tilley, \& Hayes, 1988); and that transformation of stimulus functions also applied to the contextual control of equivalence (Kohlenberg, Hayes, \& Hayes, 1991) and to consequential functions (Hayes, Kohlenberg, \& Hayes, 1991). Finally, it was shown empirically that stimulus equivalence was just one form of many arbitrarily applicable relational responses (Steele \& Hayes, 1991). That last empirical article finally put the experimental analysis of multiple stimulus relations front and center within behavior analysis and it made a simple claim: the focus of equivalence should not be so much the presence or absence of equivalence classes, rather, the focus should be on equivalencing as an example of a larger set of derived relational responses. The first written descriptions of RFT soon appeared in this same period (Hayes \& Hayes, 1989).

Sidman continued to work on a theory of stimulus equivalence, describing his contingency account around the turn of the century (Sidman, 1994; Sidman, 2000). By then RFT had appeared, but Sidman was profoundly skeptical: "I have difficulty with the notion that the process by which equivalence relations come about-'equivalencing'-must itself be a learned response" (1994, p. 556) and "For me, the mathematical description of the equivalence relation has an elegance and simplicity that relational frame theory is unable to match" (p. 559). Despite his skepticism that 'equivalencing' could be, in fact, a broad and generalizable operant, the field of behavior analysis has continued to explore that very possibility and to expand the range of relational responses that are studied.

One reason the role of Aaron Brownstein was given weight in this fly-over of the RFT research tradition, is that in the context of the times it needs to be understood that many if not most well-known behavior analysts did not see RFT as a behavioral theory of note. Brownstein was not as well known as Sidman, but he was a major basic behavior analyst. Had he been known to be a developer of the 
early RFT work, no doubt many in basic behavior analysis circles would have looked more deeply. As it was, Sidman's criticisms and the active disinterest of more senior behavior analysts severely slowed the speed of serious consideration received by this new theory.

It is worth noting in passing that Sidman's criticisms do not seem as telling when viewed across decades of research about whether relational operants exist. Mathematical descriptions do, without a doubt, have an elegance and simplicity, but so do functional operant descriptions, particularly for behavioral psychologists. Perhaps of more import, it is worth noting the limited shelf life of the word "must" in the sentence "I have difficulty with the notion that the process by which equivalence relations come about-'equivalencing' - must itself be a learned response" (1994, p. 556). Once a phenomenon is shown to exist in science, it would be an odd retort to criticize the data on the basis that the scientist is stating what "must" be. After all, statements of what exist are empirical statements, not matters of preference. Said in another way, scientific theories are tacts, not mands. In defense of Sidman, however, the data were not conclusive in 1994, so it was entirely fair to treat the possibility that relational operants exist as a preferential claim. The problem is that for many long years, and even decades, most basic behavior analytic researchers did not shift to an empirical standard of evaluation as the data came in. That had an unfortunate effect because if operant psychology is to mean anything, it needs to be able to decide if a particular action is operant or not.

\section{Relational Framing as an Operant}

RFT's canonical text, Relational Frame Theory: A Post Skinnerian Account of Human Language and Cognition (Hayes et al., 2001), synthesized twenty years of research to that point. It is now twenty years later from the publication of that book and investigators around the world have asked a wide variety of questions attempting to validate and extend the reach of key ideas within RFT as a way of helping us understand the complexity of human verbal behavior.
The term "relational frame" is used to describe a type of relational behavior. This unit, like any operant more generally, is observed at the level of the whole organism interacting in and with the environment. Frames are not presumed to be 'stored' anywhere in the organism. They are to be found in their occurrence. Skinner himself opposed the idea of 'language' as a reified object, somehow 'stored' inside the brain or otherwise in the organism (Skinner, 1976; Gross \& Fox, 2009; Sidman, 1971) and likewise in an RFT approach, humans do not store relational frames in their brains, just as they do not store 'walking behavior' in their legs.

RFT argues that the basic unit of verbal behavior is arbitrarily applicable derived relational responding under specific kinds of contextual control (Hayes et al., 2001, pp. 25-27). In more recent years the word "derived" has been treated as implied and the unit is called "Arbitrarily Applicable Relational Responding" for short, or "AARR" (or sometimes in gerund form, AARRing). Not all stimulus relations are examples. The behavior of non-humans often involves stimulus relations that are based solely on formal properties of related events. It is unsurprising when a bird is able to respond successfully to cues such as "pick the object which is larger / smaller / darker / brighter / more circular" (and so on) because relational stimulus control of that kind is as old as animal learning research. What would be surprising is if the bird were able to respond successfully to treating a dime as being 'bigger than' a nickel - that is, if relational responses could be arbitrarily applied, based on cues other than the perceptual or directly conditioned properties of related events.

AARR is characterized by three response features: mutual entailment, combinatorial entailment, and transformation of stimulus function and two forms of contextual control: relational contextual cues $\left(\mathrm{C}^{\mathrm{rel}}\right)$ and the functional contextual cues $\left(\mathrm{C}^{\mathrm{func}}\right)$.

Mutual entailment suggests that if we are taught a relationship between two objects in one direction, the relation in the other direction can be derived with no additional direct training once the relevant relational operant exists. If, for example, I were to tell you that I am a better singer than my sister, you will derive that my sister is not as good of a singer as me. 
Combinatorial entailment is similar but spans a not-directly-trained relationship between three objects. For example, if I were to tell you that I was more frugal than my sister but less frugal than my brother, you would be able say that my brother was the most frugal person amongst the three of us, though I have not directly taught you the comparison between my two siblings, because of the $\mathrm{C}^{\text {rel }}$ contextual cues that control comparative ("more" / "less") relational framing.

Transformation of Stimulus Function is said to occur when a stimulus function is based on an AARR with another stimulus, and the cues that are selecting the relevant functional dimension. Consider the case of a child who is somewhat afraid of a type of dog called a "deoji" because she was nipped by one while giving it a doggie treat. If she later learns that a jumjaw is a bigger dog than a wappa, while a deoji is a smaller dog than a wappa, based on that history she may run screaming from the room at the statement "oh look, a hungry jumjaw is coming into the house!"

This hypothetical child is not fated to forever cry and scream in fear in the presence of any and all things dog related. The child's verbal community, and other features of the environing conditions will select some features and not others under certain conditions. For example, the child may be able to look at a picture of a jumjaw and draw one perfectly well if the functional contextual cues of appearance (versus feeding) do not select for stimulus dimensions particularly relevant to the child's fear. Said in another way, fear will likely be under some degree of $\mathrm{C}^{\text {func }}$ control.

From an RFT perspective, once relational operant repertoires are well established, a person may respond verbally to nearly everything (Hayes et al., 2001, p. 48). These relational responses co-occur with non-verbal operant behaviors and can alter their stimulus control, motivating conditions, and consequential control. Said in another way, relational operants operate on other operant processes. Verbally sophisticated individuals can engage in such responding privately and as a result they experience internal stories, imaginative thoughts, or other verbal stimuli which may function to expedite, or impede, overt behaviors of all kinds.
Ongoing AARR builds elaborate relational networks that give verbal organisms advantageous efficiency in behavioral influence that can span time, space, and generations. We know that human language abilities provide the opportunity for unlimited imagination and recombination of stimuli. RFT suggests a way to analyze, predict, and teach this massively generative repertoire. Where Skinner was effective at conveying some common functions of speaker behavior, an understanding of how and why we are able to do so much with language with such relatively little learning time, is captured by the more-recent advancement of RFT.

Just as Skinner sought to delineate common speaker functions from one another, Hayes et al., (2001) list numerous forms of relational framing that can be combined into verbal networks. These include: hierarchical frames, frames of coordination, frames of opposition, deictic frames, and many others (Hayes et al., 2001). These instances of framing combine to form networks that in turn can be combined in rules, analogies, metaphors, and stories.

In the early days of RFT research, evidence of the operant nature of relational performances was largely based on indirect features. Operants should develop, for example, and should be sensitive to antecedent and consequential control. As evidence emerged that were supportive of these implications, more direct experimental tests gradually emerged in which children or other populations that lacked particular forms of relational responding were trained through operant methods that relied on multiple exemplars to display particular relational operants.

This literature is now quite voluminous and, thus, a challenge to summarize. Our solution in this paper is to take a small set of examples and to do a more adequate review of what is known there, while waving a hand at the larger body of work that is available. In what follows we will briefly examine how development and training is studied in derived relational responding; and will then link those ideas to the measurement and establishment of deictic relations and perspective-taking as a concrete example of how the idea that "relating is an operant" has impacted RFT applications and research. 


\section{Development and Shaping}

Developmental theories commonly embrace a proposition that "...individuals pass through an invariant sequence of qualitatively different stages or levels of structural development" (Sullivan et al., 1970), varying primarily in the rate at which an individual progresses (or does not progress) through the developmental stages.

Behavioral theories of development tend to be more flexible. While it is assumed that all complex actions evolve from simpler forms based on interactions with the environment phylogenetically and ontogenetically, the idiographic pathway through acquisition of complexity may differ.

Operants are developmental phenomena of that latter kind. They emerge, but the exact pathway depends on the history of the individual interacting in and with a context and the complexity of the task. We can assume that most learners are exposed to common cultural contingencies over time, but the contingencies of reinforcement are the point of emphasis. For that reason, while there are broad agelinked performances in RFT research (McHugh, Barnes-Holmes, \& Barnes-Holmes, 2004a, 2004b), longitudinal studies are of central importance, especially when linked to experimental analyses and deliberate attempts at training.

For example, Lipkens, Hayes, and Hayes (1993) tracked the emergence of features of equivalence, frames of distinction (or "exclusion"), and mutual entailment based on frames of distinction in a single infant, and found that these performances gradually emerged from simpler to more complex forms, as would be expected if they were in part learned. Luciano, Becerra, and Valverde (2007) found similar developmental sequences in an infant, but also found that these trends could be modified by training, as would be expected if these performances were operant.

A large number of studies have found that relational framing is susceptible to training. Much (but not all) of this research is focused on people with intellectual and developmental disabilities (IDD). Many children and adults with IDD demonstrate delays in the acquisition of relational repertoires, though research has suggested that interventions using derived stimulus relations can result in improvement in these areas.

Several studies with neurotypical children and children diagnosed with autism have found that multiple exemplar training focus on relational operants results in improvement in both groups (e.g., Gorham, Barnes-Holmes, Barnes-Holmes, \& Berens, 2009; Murphy \& Barnes-Holmes, 2010; Murphy, Barnes-Holmes, \& Barnes-Holmes, 2003). When research has focused on children with more severe delays, the benefits of relational training continue to be evidenced. For example, Rehfeldt and Root (2005) sought to establish derived relational requesting skills in three adults with severe IDD (IQs of less than 30). At baseline, none of the participants reliably exhibited tacting or textual behavior, matching words to pictures (or vice versa), or using derived requesting. After relational training all participants could match words to picture (and vice versa) with at least $89 \%$ accuracy and demonstrated derived requesting for at least two items.

Relational operants develop, and their development can be accelerated in both neurotypical populations and those with developmental disabilities by contingent reinforcement linked to multiple exemplar training. These classes of behavior impact human repertoires in profound ways-of note for our purposes: sense of self, intelligence, and metaphorical extension.

Sense of Self/Deictic Relations. One of the earliest hypotheses that emerged from RFT was that noticing one's own behavior from a consistent perspective or point of view may be linked to deictic relational framing (Hayes, 1984). Deictic relations can only be learned by demonstration because they depend on the perspective of the speaker or listener. Examples include relations of person (e.g., "I/you"), place (e.g., "here/there") and time (e.g., "now/then"). Cognitive relations of this kind appear to be a key feature of social and cognitive development (Weil, Hayes, \& Capurro, 2011) and multiple exemplar training has demonstrated some success in training these forms of relational framing (Barnes-Holmes, Barnes-Holmes, Smeets, \& Friman, 2004; Dymond \& Barnes-Holmes, 1998; Hayes, Fox et al., 2001; Lovett, 2012; McHugh et al., 2009). Over the arc of RFT research, deictic 
relations have been found to be successfully acquired by a multitude of participant types through use of a multiple exemplar training procedures, such as with young children (Weil et al., 2011) and adults (Montoya-Rodríguez, McHugh, \& MolinaCobos, 2017).

The impact of multiple exemplar training on deictic relations is important because in mainstream psychological literature, perspective-taking is generally thought of as a cognitive process which develops independently of environmental stimulation (Weil et al., 2011). Historically, research on perspective-taking has been densely limited to fields such as cognitive and developmental psychology, especially when cross-sectional developmental profiles have been employed. Behavior analytic studies using perspective-taking training have been growing, however (McHugh et al., 2009; Moran \& McHugh, 2019).

Cognitive and developmental psychologists have found that perspective-taking abilities begin to emerge in children around the age of two (Wellman \& Lagattuta, 2004). The continuation of the development of these abilities occurs through levels of complex verbal behavior as the child talks about their emotions and other mental states with others (Wellman \& Lagattuta, 2004). Preliminary behavioral research has supported this finding by demonstrating a clear developmental trend in the ability to perform relational perspective-taking tasks (by both relational type and relational complexity) starting in early childhood and progressing through adulthood. Studies have suggested that perspective-taking abilities present in interpersonal and spatial relational stimuli are not present in children under the age of four; at times such relational repertoires may not be flexible or may be difficult to establish even in older children (Barnes-Holmes, 2001). Personal and spatial deictic relations appear to emerge before temporal relations ( $\mathrm{McHugh}$ et al., 2004a, 2004b.) Verbal hierarchies emerge, according to operant theory, not due to the passage of time however, but a history of interactions with contingencies of reinforcement. If deictic framing is an operant class, it should be teachable with carefully designed learning environments.

Current evidence supports this idea. Studies specifically targeting perspective-taking through the use of multiple exemplar training, have shown improvement both in typically developing children (Davlin, Rehfeldt, \& Lovett, 2011), and neuro-diverse populations (Jolliffe \& Baron-Cohen, 1999; Kaland, Smith, \& Mortensen, 2008). For example, a study using multiple exemplar training with people with a diagnosis of Down syndrome (Montoya-Rodríguez, Molina-Cobos, \& McHugh, 2017; Montoya-Rodríguez \& Molina-Cobos, 2019), demonstrated multiple exemplar training was successful in shaping improvement in participants' perspective-taking skills. There are data suggesting that teaching deictic relations may have an effect on Theory of Mind (ToM) skills (Weil et al., 2011), but the relation is not a simple one. Subsequent research has shown that improvement due to training on the ability to reverse deictic relations does not necessarily change Theory of Mind performance (Montoya-Rodríguez \& Molina-Cobos, 2016) and that the details of training matter. From an operant perspective, these findings give broad support to the idea that we can treat ToM as a series of relational (deictically-involved) operant classes but they also emphasize that the details of the specific relations appear to matter, not just as a means of shaping ToM skills, but in the management of other areas of human complexity such as how emotions are described or addressed by behavior (Moran \& McHugh, 2019).

The idea that a 'sense of self', can be thought of as a series of learned operant verbal classes, underlies many effective therapeutic approaches such as ACT. The literature on ACT is vast (e.g., see bit.ly/ ACTRCTs) and not pertinent here per se. Of importance, though, is the notion that the behavior of 'selfing' can be learned and altered by contingencies. When seen in the light of radically functional operant classes, verbalizing about one's experiences, self-reflections, hopes, and goals, (and that of others) may be found to be at the heart of many issues. From ToM, to an analysis of the behavioral functions which impact challenging questions about 'who we are' and 'what we want out of life' to name a few (Hayes, Law, Malady, Zhu, \& Bai, 2020; Dixon et al., 2020). Evidence to date strongly suggests that deictic framing can be adequately treated as a series of operant classes. 


\section{Intelligence}

Another area in which training of relational operants has grown a substantial empirical base is in the development of relational reasoning skills as measured by intelligence tests. "Intelligence" has long been a catch-all, broad measure of our ability to interact with language functions. A primary feature of standardized assessments and intelligence testing is percentile scoring compared against norm-referenced outcomes, which indicate how an individual's test scores compare to other scores. This information is of particular interest to developmental researchers, as it provides consistent data on where an individual stands in relation to the standard deviation from the mean. This knowledge can be used to infer developmental trends and contextual features which may alter the development of relational framing abilities. However, historically, intelligence has been thought to be tremendously difficult to impact through training (i.e. Hunt, 2014)

The concept of "intelligence" is overly broad when analyzed through the lens of behavioral psychology. Relational operants have provided a new way to bridge these research traditions (McLoughlin, Tyndall, \& Pereira, 2020; Gore, Barnes-Holmes, \& Murphy, 2010; Vizcaíno-Torres et al., 2015). The 'bottom-up' approach of behavior analysis, studying direct-contingency learning, has built the foundation for complex verbal repertoires. Behavior analytic approaches are beginning to provide insight into more complex cognitive processes, and to provide effective technology for shaping things like what might be generalized as 'intelligence' through technologies which treat IQ as the byproduct of many naturalistic classes of verbal relating and reasoning. Intervention technologies such as Strengthening Mental Abilities through Relational Training (SMART) and Promoting Emergence of Advanced Knowledge (PEAK) are focused on evaluating mastery of relational repertoires. If intelligence is composed of a series of verbal operant classes, those classes ought to be teachable under certain conditions. Evaluations as to the effect of SMART, PEAK, and other relational learning technologies are beginning to demonstrate good effects with increasing size and scope (i.e., Colbert, Tyndall, Roche, \& Cassidy, 2018). Moving IQ scores by a stan- dard deviation or more is not something which an RFT approach to intelligence is finding out of reach. On the contrary, with the right environmental designs, and a functional operant unit of analysis-cognitive improvement can apparently be shaped much as with other kinds of behavioral classes.

This work began correlationally. O'Hora et al. (2008) conducted a study which demonstrated the ability to respond to temporal relations and subsequent predictions of performance on cognitive tasks. They found that participants who passed the temporal relational task did not score any higher in the Working Memory or Processing Speed subtests but did score higher in the Verbal Comprehension and Perceptual Organization categories of the WAIS-III. The results of this study correlate with the suggestion that distinct behavioral repertoires and relational responding contribute to different human behaviors which can come under separate sources of control (O'Hora et al., 2008). Dixon, Belisle, and Stanley (2018) evaluated the relationship between standardized intelligence assessment and derived relational responding, measured using the PEAK Pre-Assessment, in individuals with IDD. Intelligence testing scores (via WISC-IV) of the participants ranged from 48 to 132 with $95 \%$ of participants demonstrating an IQ less than 100. Higher IQ scoring corresponded with higher derived relational responding scores (Dixon et al., 2018).

In the first experimental RFT training study focused on IQ, Cassidy, Roche, Colbert, Stewart, and Grey (2016) investigated the use of relational frame skills training to increase intelligence quotients in both neurotypical individuals and individuals with IDD. The first experiment of the study investigated individuals aged 10 to 12 with no known IDD. After undergoing relational framing training over the span of several months, researchers found overall significant increases in each participants' full-scale IQ of at least one standard deviation (Cassidy et al., 2016). The second experiment investigated individuals ages 15 to 17 , none diagnosed with IDD or other clinically significant learning difficulties. After delivering the same relational framing intervention as conducted in Experiment 1, increases in both verbal and numerical reasoning were recorded for all participants, though the extent of improvement was greater in Experiment 1 (Cassidy et al., 2016). 
The prediction of RFT, in stating that 'relating is an operant' is that verbal reasoning can be taught through contingency learning. While carefully thought out, multiple exemplar training technologies and methods are not yet relatively widespread, but their effects are becoming increasingly clear. Intelligence is a series of hierarchically-built operant units. RFT curricula and assessments are becoming increasingly complex and sophisticated at targeting these operants. In other words, according to the behavior analytic perspective, to a larger degree than previously supposed we can impact how 'smart' we are by designing effective instruction aimed at that purpose. IQ is not destiny. On the contrary, under the right conditions, with consideration of the right operant units in the right hierarchical order, it may be possible to increase 'intelligence' quite significantly. Very large and very well controlled studies are now underway that test that possibility and the field will soon know the answers.

\section{Analogy and Metaphor: Relating Complex Relational Networks}

"The derivation and use of analogies and metaphors is one of the most productive aspects of human responding" (Lipkens \& Hayes, 2009, p.105). Analogical and metaphorical extension is vital to the acquisition of understanding, particularly for phenomena which are difficult to access through direct experience. For example, a teacher may explain to a student that "mitochondria are like microscopic power plants that power cells" and a

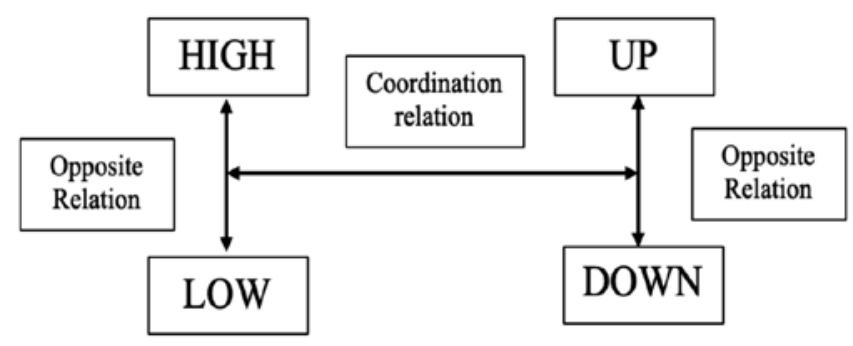

Figure 1: A relational network in which the frames of opposition between High and Low as well as Up and Down participate in a frame of coordination with one another. child may now better understand the world around them, without directly experiencing how parts of cells operate.

From an RFT perspective, these are higher-order forms of relational responding in that it is not merely relata being related, but rather a relation is being drawn between sets of relations (Foody et al., 2014). Consider Figure 1, which displays two sets of stimuli in frames of opposition with one another, with these two sets of stimuli related in a frame of coordination. This network can be described verbally as the statement "High is to Low as Up is to Down."

Let us briefly expand upon this simple network by using the example of a verbal child who has not yet learned what the words "high" and "low" mean but who knows "up" and "down". A parent teaching this child to search for objects in a room using the words "high" and "low" may start by telling the child to look for objects that are "up" and objects that are "down." Once the child has become proficient at searching for objects that are in higher surfaces and lower surfaces in response to the stimuli "up" or "down," the parent may introduce the words "high" and "low" into the relational network. The parent can say "high is to low like up is to down" and the child may derive the response of looking up when they hear "high" and looking down when they hear "low." While this particular example may appear to have non-arbitrary features in that the responses that the child engages in with respect to both sets of stimuli are the same, this simple network may now be connected with numerous other networks and the relationship between "high" and "low" can be applied in more contexts. The parent, after a long day at work, may be tired and tell their child that they are feeling "low", in which case the child may derive that their parent will be feeling better when they physically carry their head higher and look "up." This same derivation of relations between relations can be harnessed by a skilled therapist in order to help a client alter their behavioral patterns with respect to the various struggles they may face including chronic pain (Buhrman et al., 2013; Kemani, Hesser, Olsson, Lekander, \& Wicksell, 2016; Wetherell et al., 2011), trauma and PTSD (Twohig, 2009; Walser \& Westrup, 2007), depression (Folke, Parling, \& Melin, 2012; Forman, 
Herbert, Moitra, Yeomans, \& Geller, 2007; Forman et al., 2012; Zettle, 2015), anxiety (Arch et al., 2012; Eifert et al., 2009), and others.

Barnes, Hegarty, and Smeets' (1997) findings suggested that the ability to reason through the use of analogies may come as a result of increased age and thus more exposure to naturalistic multiple exemplar training throughout one's life. As this is a functional-analytic perspective on complex human functioning, it is the increased exposure to multiple exemplars aspect of this possibility, which is meaningful, not the age at which this training occurs.

A study by Stewart, Barnes-Holmes, Roche, and Smeets (2001) further examined the RFT analysis of analogy through a series of three experiments. Their results led the researchers to note that the data "support the suggestion that the abstraction of a formal stimulus dimension via equivalenceequivalence responding may provide a functional analysis" of human understanding and responding to analogical language (Stewart, Barnes-Holmes, Roche, \& Smeets, 2002, p. 393).

Deriving relations, and also relations among relations, are an important aspect of social success, with deep ties to knowledge and ways of understanding new ideas quickly, and expanding those ideas into other facets of life. These relational skills allow us to process emotional responses, to learn new skills, tell better jokes, or be better readers and writers. Metaphorical extension seems to be at the heart of many important skills and social phenomena. Here again, evidence supports that multiple exemplar training may lead to generalized operants which can help people produce and understand metaphors and analogies.

\section{Coherence and Verbal Functions as Consequences}

The verbal community often arranges verbal stimuli into relatively small and large patterns. Traditions emerge. Good stories have endings. 'Spoilers' to our favorite shows are aversive. Sentences have structure. Some grammatical errors, really bother - people (... yes, we did that on purpose). Our learned histories with respect to these patterns can take on reinforcing properties. Commonsense examples of coherent relational networks functioning as reinforcers are easy to find. Verbal stimuli can function as consequences.

Roche, Barnes-Holmes, Barnes-Holmes, Stewart and O'Hora (2002) synthesize this point effectively by writing "RFT predicts that correspondences in a relational network (i.e., verbal coheren$c e$ ) will function as a relatively powerful reinforcer for relational activity itself, and that this (is) an important feature of the verbal behavior of most individuals ... It should not be surprising ... if verbal consistency, and behavior-behavior consistency more generally, were to become a conditioned reinforcer for verbal behavior itself." (p. 78). In short, coherence is one consequence that maintains relational responding.

The quality of coherence for a relational response, in fact, is not an absolute feature, but it is evaluated with respect to a model, a paradigm, or, in this case, the expectations of the verbal community. Hughes and Barnes-Holmes (2011) report a definition of coherent relational network built on the consequences coming from the community. A relational network is coherent: "when all the individual elements relate to each other in a manner that is consistent with the provision of direct consequences typically presented by the verbal community for such relational responding" (p. 103).

One example of a research technology pertinent to the functional analysis of rules, is the Relational Evaluation Procedure (REP). It has been presented as a method to "allow the subjects to report on, or evaluate, the stimulus relation or relations that are presented (to) them on a given task" (p. 240). The advantage of REP compared to the use of the matching-to-sample is the possibility to train the participants on multiple stimulus relations (for example, same, opposite, different, more than/less than, before/after, belongs to, inclusion, ...), developing ex novo arbitrary contextual cues (for example, BEFORE can become "XXX" and AFTER can become "VVV" after training, see Hayes \& Barnes, 1997), and then asking the participants, during the testing phase, to evaluate the (trained) relational network of stimuli as correct or incorrect, or as the same or the opposite, when presented with specific (trained) contextual cues (Cullinan, Barnes-Holmes, \& Smeets, 1998; 
Cullinan, Barnes-Holmes, \& Smeets, 2000, 2001; Hayes, Stewart, \& McElwee, 2016, 2017; Hayes \& Barnes, 1997; Hayes et al., 2001; Smeets, BarnesHolmes, \& Striefel, 2006; Smeets, Wijngaarden, Barnes-Holmes, \& Cullinan, 2004; Stewart, Barnes-Holmes, \& Roche, 2004).

Devany et al. (1986) provided an early empirical demonstration of coherence as a reinforcer as participants were taught equivalence classes and alternative forms of prompting and reinforcement were removed. The authors note that participants "showed improvement in test performance across blocks of test trials... The improvement suggests that reinforcement of correct responding was occuring ...however, responses were neither explicitly rewarded nor punished in the test phase."(p.254).

Technological developments to test for coherent relational networks have provided demonstrations of establishing ad hoc analysis of learned relational networks. Quinones and Hayes (2014) note that:

\begin{abstract}
From a real-world standpoint, many of the possible stimulus relations people detect are logically ambiguous, but that does not mean that they are psychologically ambiguous...Cognitive errors may at times be trained in whole cloth, but the more dominant situation appears to be one in which a key relational feature leads to a kind of cognitive cascade as people try to make verbal sense of their world." (pp. 91-92)
\end{abstract}

Logically, responses to coherent, practiced, relational networks with extended histories of reinforcement, ought to bring about certain features of responding under specific conditions. Namely, repertoires with rich histories are likely to be quick, strong, and difficult to alter with new shaping. When given a contextual cue, brief immediate relational responses are likely to occur (BIRR), followed potentially by extended and elaborated relational responses (EERR) with regard to a wider array of stimuli. Technologies such as the Implicit Relational Assessment Procedure (IRAP) have assessed these differences (Barnes-Holmes, Barnes-Holmes, \& Stewart, 2010). Though the IRAP has been altered to suit many needs, the general premise is that it is a tool which can detect 'implicit biases' - said another way, a history of reinforcement. Coherent networks are challenging to ignore. The IRAP has been evaluated in many contexts (Drake et al., 2010; Hughes \& Barnes-Holmes, 2013; Power, BarnesHolmes, Barnes-Holmes, \& Stewart, 2009)—for example, as a means of detecting bias towards/ against races/cultures (Barnes-Holmes, Murphy, Barnes-Holmes, \& Stewart, 2010), ages (Cullen, Barnes-Holmes, Barnes-Holmes, \& Stewart, 2009), trained information (Al-Nassar, 2020), and 'slimness' (Roddy, Stewart, Barnes-Holmes, 2010). There has been several criticisms lodged about the IRAP for technical reasons, but other means of addressing assessment of an extensive history of coherent responding exist that appear to avoid the problems of the traditional IRAP and that use RFT concepts (e.g., Levin, Hayes, \& Waltz, 2010; O'Reilly, Roche, Ruiz, Tyndall, \& Gavin, 2012).

Coherent relational networks present some challenges due to their idiographic nature. They are found in the individual histories of verballysophisticated humans. The premise that extended histories can be detected and altered through new contingencies remains well-supported by the current research. Coherent networks may help us understand, predict, and influence many important events of human interest such as bias or 'extremist' behaviors.

\section{Rule-Governed Behavior}

Skinner first defined rules as stimuli that altered operant or respondent properties of other stimuli (Skinner, 1957). He sometimes referred to rules as "contingency-specifying stimuli" (Skinner, 1969). However, Skinner's conceptualization of how stimuli were specified was left unaccounted for. RFT would later provide the missing conceptualization for how stimuli may be specified. Skinner also highlighted the importance of rule-governed behavior when he suggested rule-following may allow for rapid acquisition of complex behavior relative to contact with direct-acting contingencies alone (Skinner, 1989).

Rule-governed behavior has generally been understood as a response to a verbal antecedent (Hayes et al., 2001). Our ability to understand rules undoubtedly impacts our interaction with events 
and stimuli though it should be acknowledged that given the previously-mentioned ubiquity of verbal functions in much of human life, delineating rulegoverned and contingency-shaped behavior can be a challenge given how intertwined they are. Any stimulating characteristic of the environment that is already established within a relational frame is necessarily a verbal antecedent stimulus. And because verbal behavior co-occurs with experienced events almost constantly, one is hard-pressed to conceptualize, much less demonstrate that a given response is the sole byproduct of rule-governance or contingency shaping.

Consider a person who is told "Don't touch the stove top when it is glowing red". They may actively avoid touching it without ever having been close enough to feel the heat. Though they have never experienced the direct aversive contingency of touching a hot stove, their behavior would suggest that they have been shaped. Given the rule-governed functions, we may simply say that the person 'understood' the rule. Given, then, an assumption of transformation of stimulus function, the person may go on to avoid a ceramic pot coming out of a kiln which is glowing red without needing another specific rule. It is a behavioral event which allows the person to be insensitive to some direct-acting contingencies, and perhaps may bring about effective action more readily upon other occasions.

\section{Empirical Research on Establishing Rule-Governed Behavior}

Given relational frame theory's position that relational responding is a generalized operant which is learned through multiple exemplar training, it is important that research investigates the conditions under which rule-following is learned. Because of this, various lines of research have evaluated the use of multiple exemplar training on rule-following for those lacking such repertoires. Again, if relating is an operant, we should be able to teach it through reinforcement learning. The key tests for rule governed behavior and self-rule governed behavior are specific arrangements that, if the theory accurately describes the phenomenon, result in behavioral outcomes that are otherwise unlikely. Due to the challenge, topographical analyses of verbal behavior do not capture our true interest in relational responding. We could, after all, teach a parrot to say many things that may look like complex language-but it is difficult to really parse the function of verbal behavior from its form. This is, in part, why most basic RFT procedures attempt to replicate relational learning progressions with entirely novel stimulus sets.

One of many demonstrations of this used multiple exemplar training to teach children diagnosed with autism with no rule-following repertoire to follow rules using RFT as a guide to identifying the necessary skills (Tarbox, Zuckerman, Bishop, Olive, \& O'Hora., 2011). The participants had a developed repertoire of mands, tacts, and one step instructions, but no repertoire of responding to 'if-then' statements appropriately prior to enrollment in the study. Multiple exemplar training was successful in teaching the children to respond to 'if-then' rules, and such responding generalized to novel 'if-then' rules (as in, "if I am able to sit through this class, then I can go to the park"). A generalized operant which is easy to imagine as a life-changer for both the learner and their care-providers.

Other research has used rules as a part of a training package to successfully teach children with autism how to detect and appropriately respond to sarcasm (Persicke, Tarbox, Ranick, \& St. Clair, 2013). Appropriate responding to sarcasm generalized to novel exemplars. Participants involved in this research had repertoires which involved prior training of prosody (voice volume control), body language and facial expressions, physical context of conversation, conversational audience, desires, emotions, sensory perspective taking, cause and effect, preferences, knowing, beliefs and intentions. Understanding sarcasm and metaphorical extension is stereotypically considered to be a hallmark of Autism Spectrum Disorders-but studies such as this suggest that the skill is a teachable response; it is a repertoire that can be altered by rules that are taught.

Workable rule following requires sensitivity to contextual indicators of when contingencies in the present moment shift. Many of the empirical procedures for assessing the impact of contingency 
shifting use computer game-like procedures (e.g. press buttons to move the object to the goal to get a point, or match to sample) and systematically alter the relationship between button pressing and object movement or the characteristic of the sample that satisfies the matching criterion. In this way, common language can be used as the verbal antecedents and novel languages do not need to be trained. Research has also incorporated standardized procedures such as the Wisconsin Card Sort Task (Berg, 1948) and the Contingency-shifting variant Iowa Gambling Task. (Dymond, Cella, Cooper, \& Turnbull, 2010; Turnbull et al., 2006). Patterns of rule governed responding to contingency shifting procedures reflect differential histories of social mediated reinforcement for rule following per se (pliance) or rule following due to reinforcing coherence with the arrangement of the environment (tracking).

The RFT literature, at times, categorizes rule governed behavior within the category of pragmatic verbal analysis. A basic account of pragmatic verbal analysis as relational responding to previously established relations, or relating relations, is evidenced by McLoughlin and Stewart's (2017) construction and demonstration of responding to relations among relations with novel stimuli, and Harte et al.s (2020) extension in which they showed differential effects of novel derived relational responses on resurgence of pliance functions during extinction. Further within pragmatic verbal analysis, rule-governed behavior interacts with perspective taking repertoires resulting in self-rule governed behavior. For the most recent systematic review we refer readers to Kissi et al. (2017).

\section{Contingency Sensitivity and Pliance}

An early finding from investigating rule governed behavior was that it was frequently associated with 'insensitivity' to changing contingencies (Catania, Shimoff, \& Matthews, 1989). Given the complexities of the world, and our verbal interactions with it, it is not difficult to imagine that sometimes rules serve us better than direct-contingencies, but that also sometimes we stick with rules even when they are clearly not working for us. This 'insensitivity' to direct-acting contingencies is somewhat unique to humans, and is often referred to as the "insensitivity effect" or "contingency insensitivity". The insensitivity effect has been shown to be moderated by the presence or absence of the rule-provider (KrogerCosta \& Abreu-Rodrigues, 2012), history of following rules (Martinez-Sanchez \& Ribes-Inesta, 1996), accuracy of the instruction (Hojo, 2002) and psychological suffering (Baruch, Kanter, Busch, Richardson, \& Barnes-Holmes, 2007; McAuliffe, Hughes, \& Barnes-Holmes, 2014). It should be noted that the insensitivity effect does not imply insensitivity to the contingencies per se. Instead, it has been conceptualized that because rule-following involves contingent reinforcement, the involvement of rules increases the number of participating contingencies. As such, in these experiments, there are multiple conceptual contingency streams; contingencies which are said to be direct-acting, and others which are verbally mediated.

It was initially hypothesized that pliance (loosely: when rules are followed as a function of our history with the stimulational properties of the rulegiver and the rule-giving environment) functions might induce a higher degree of the insensitivity effect based on the assumption that most people have a substantial history of following rules from various speakers (Zettle \& Hayes, 1982). Since then, a handful of studies have investigated the relationship between the nature of the environmental and historical features of rule provision and the insensitivity effect. The difficulty with such research is it is often hard to determine what kinds of features or a rule-giver, can be safely, and relatively universally assumed to have a history of reinforcement. For example, a person in a police uniform may be likely to elicit compliance for many, but not others, and it is difficult to identify the features of the uniform and person needed to safely assume that participants have some history of reinforcement with those stimuli.

Pliance research has suggested that rules may function to yield more resistance to extinction (Henley, Hirst, Reed, Becirevic, \& Reed, 2017; Miller, Hirst, Kaplan, DiGennaro, \& Reed., 2014; Zettle \& Young, 1987) or minimally impact performance (Baruch et al., 2007). Participants with dysmorphia and/or depressive thoughts may exhibit 
the insensitivity effect more significantly (McAuliffe et al., 2014). However, experiments concerned with the insensitivity effect for participants with symptoms of depression have been inconsistent (Baruch et al., 2007; McAuliffe et al., 2014). McAuliffe, Hughes and Barnes-Holmes (2014) highlight three differences in their study that may account for this discrepancy with previous findings. First, McAuliffe et al. (2014) manipulated accurate and inaccurate rules between groups while previous research (Baruch et al., 2007) made these manipulations within participants. In other words, the rule participants received was accurate before the contingency shifted, rendering the rule inaccurate, while the participants in the later research (McAuliffe et al., 2014) who received the inaccurate rule had no history of the rule being accurate. The second distinction is while McAuliffe et al. (2014) evaluated the effects of pliance and tracking, they did so in a separate experiment, while Baruch et al. (2007) evaluated the interaction between the rule type (a ply or a track) with the changing contingency, rather than accuracy of the rule independently. The final distinction is that while Baruch et al. (2007) used a match-tosample procedure, the later research (McAuliffe et al., 2014) utilized a manipulation between schedules of reinforcement for high and low rates of responding (for experiment one).

In three experiments, researchers investigated moderators of pliance (Donadeli \& Strapasson, 2015). The moderators analyzed included (1) the capacity of the speaker to monitor the listener's behavior, (2) the ability of the speaker to supply consequences for the listener's compliance or noncompliance with the rule and (3) the nature of the consequences delivered. The results indicated that the insensitivity effect was most significant when participants were monitored by the rule-giver and the rule-giver reprimanded participants for defying the rule even when the rule was an inaccurate depiction of the contingency.

With respect to 'the insensitivity effect', one's history with the rule is an important variable. Researchers (Harte, Barnes-Holmes, BarnesHolmes, \& McEnteggart., 2018) found that rule following was less sensitive to direct contingencies when the rules presented were low in derivation whether relations were trained through mu- tual or combinatorial entailment. Derivation in this experiment referred to the amount of training blocks during the Implicit Relational Assessment Procedure (IRAP). Low derivation implies a richer history with the rule, while high derivation implies less history with the rule.

Research on pliance has also been conducted in applied contexts. For example, researchers evaluated the impact of a "buckle up" sign (ply) on seatbuckling behavior among drivers leaving a college parking lot (Berry, Geller, Calef, \& Calef, 1992). In some conditions, an observer would be present in addition to the sign. Contingent on the driver buckling up, the message "thank you for buckling up" would be displayed. Results showed that the presence of the sign increased seat-buckling behavior among the drivers. These benefits were increased even more so in the presence of an observer. However, the mere presence of an observer in the absence of the sign, made no difference on seat-buckling behavior.

\section{Empirical Research on Augmentals}

Research in the area of motivative augmentals (verbal stimuli which alter the value of a consequence) typically involves selecting verbal stimuli and examining their effects on behaviors which are freely available to engage in. If in the presence of the verbal stimulus identified, the rate, intensity or latency of the behavior defined as the dependent variable is modified, the verbal stimulus can be conceptualized as a motivative augmental.

Research has been conducted in order to demonstrate an experimental model of formative augmenting (Whelan \& Barnes-Holmes, 2004). In the first experiment, the consequential functions (i.e. positive reinforcement/positive punishment) of one stimulus successfully transformed the consequential functions of a neutral stimulus through combinatorial entailment using frames of opposition and coordination. The second experiment had a similar procedure, but instead of transforming stimulus functions using frames of opposition and coordination, frames of 'more-than' and 'less-than' were utilized. The second experiment, like the first, was successful in transforming the targeted stimulus functions. 
In another, free-operant experiment, a hidden experimenter would say the name of a freely available reinforcer (e.g. "Cheerio") on a variable interval schedule. The results of the experiment showed that the reinforcer most frequently selected by the participants corresponded with the reinforcer that was most frequently being named by the hidden experimenter (Ju \& Hayes, 2008)

Research has been conducted with relevance to motivative augmentals in the context of storytelling (Valdivia, Luciano, \& Molina, 2006). In their experiment, verbal statements in the proper context, due to their sensory functions, were shown to function as establishing operations for behaviors such as drinking water and stretching. The study involved different stories being told to children and measuring behaviors such as stretching amongst the children listening. Results showed that when participants were told a story about being in a desert, involving many words referring to the immense heat and feelings of thirst, they drank more water relative to other conditions. Similarly, in a condition in which the participants were told a story about being trapped in a box, they engaged in more stretching behavior relative to other conditions.

Jackson et al. (2016) evaluated IRAP-anchored motivative statements in the context of a cycling class and found that when the cyclists interacted with personalized rules regarding their goals in the class, they burned more calories than when presented with incongruous or nonspecific motivative statements such as "good job!". Other research similarly evaluated the use of the IRAP to select verbal stimuli that may function as motivative augmentals (Rafacz et al., 2019). Experiments such as these, demonstrate that rule-governance is deeply tied to a history of reinforcement, and that rules which can tap into strong, and frequently reinforced relational networks are likely to be effective.

\section{Forging Ahead}

There is a long list of missing topics in this chapter: the implications of transformation of stimulus functions, applications to clinical psychotherapy, and an exploration of the relationship between RFT and neurological and biological correlates just to name a few. Our goal has been to sample enough topics to show that RFT allows serious consideration of many of the major issues engaged by research on human language and higher cognition.

Creating a scientific psychology of complex human behavior has struggled to free itself of mystically-oriented, and ideologically-guided constructions. The progressive study of human complexity requires continued diligence and advocacy for a careful naturalistic approach. The only way to study the functions of verbal stimuli is to understand them at the level which they occur-as interactions between the human being and their contingencies of reinforcement.

Purely functional accounts of learning are challenging to hold on to. Nowhere is that truer than in the area of language and cognition. It is equally important to avoid the overgeneralization of behavioral terms. The language of associative learning can readily account for human cognition only by stretching its basic units beyond recognition. Skinner's functional approach avoided that problem but extended the functional unit to a sociological level. Relational operants do not have that problem.

The need to understand language and cognition has a sense of urgency to it. The dangers facing the world, which have a lack of understanding of human behavior as their root cause, have only grown since Skinner's call to action in (1976). Climate change, social justice, immigration and other issues concerning the responsible prediction and influence of human behavior have continued to be met with inadequate solutions (for discussions of the current and potential impact of behavior science upon these areas see: Atkins, Wilson, \& Hayes, 2019; Biglan, 2015). While discussions of dissemination and broad adoption of behavioral scientific principles abound within the field, the challenge of rising to the upper limits of possibilities for behavioral scientific impact, largely remains. Applications of RFT, we hope it is clear, represent a way to address human verbal complexity in new and exciting ways. The places which an understanding of rules, metaphorical extension, human intelligence, and sense of self, can take us-are near limitless.

The contextual wing of behavioral science is poised to create partnerships with other sciences 
in many areas. Rapid progress has been made with evolutionary science (Wilson \& Hayes, 2018) and concrete gains have been made with intervention science (e.g., Hofmann, \& Hayes, 2020), and cognitive science (DeHouwer \& Hughes, 2020). As behavioral science has impacted these areas, key features of the behavior analytic tradition, such as the idiographic approach of Sidman, have received new and positive attention (Law \& Hayes, 2020). But these alliances also demand that behavior analysis broadens its view of human language and higher cognition. That will not be easy. Framing relationally, as a broad operant class, challenges behavior analysts to rethink some previous assumptions. It is an empirical fact that verbal stimuli can impact other behavioral processes. That suggests that relational operants will have a major impact on our field as we work through how verbal behavior participates in complex human behavior. Verbal stimuli grow the possibilities of human complexity exponentially. Despite the analytic difficulties that result, behavior analysis must take bold leaps if it is to move toward a more complete science of human behavior. The world needs nothing less.

\section{References}

Al-Nasser, T. (2020). A component and process analysis of the impact of enhanced self-instructional packets on behavioral programming. Unpublished doctoral dissertation. University of Nevada, Reno.

Arch, J., Eifert, G. H., Davies, C., Plumb, Vilardaga, J. C., Rose, R. D., \& Craske, M. G. (2012). Randomized clinical trial of cognitive behavioral therapy (CBT) versus acceptance and commitment therapy (ACT) for mixed anxiety disorders. Journal of Consulting and Clinical Psychology, 80(5), 750-765. http://doi.org/ $10.1037 / \mathrm{a} 0028310$

Atkins, P. W., Wilson, D. S., \& Hayes, S. C. (2019). Prosocial: using evolutionary science to build productive, equitable, and collaborative groups. New Harbinger Publications.

Baer, D. M., Peterson, R. F., \& Sherman, J. A. (1967). The development of imitation by reinforcing behavioral similarity to a model. Journal of the Experimental Analysis of Behavior, 10, 405-416. http://doi.org/ 10.1901/jeab.1967.10-405

Barnes, D., Hegarty, N., \& Smeets, P. M. (1997). Relating equivalence relations to equivalence relations: A relational framing model of complex human functioning. The Analysis of Verbal Behavior, 14, 57-83. http://doi.org/ 10.1007/ BF03392916

Barnes-Holmes, Y. (2001) Analysing Relational Frames: Studying Language and Cognition in Young Children. (Unpublished doctoral thesis). National University of Ireland, Maynooth, Ireland.

Barnes-Holmes, Y., Barnes-Holmes, D., Smeets, P. M., \& Friman, P. (2004). Establishing relational responding in accordance with more-than and less-than as generalized operant behavior in young children. International Journal of Psychology and Psychological Therapy, 4, 531558.

Barnes-Holmes, D., Barnes-Holmes, Y., \& Stewart, I. (2010). A sketch of the Implicit Relational Assessment Procedure (IRAP) and the Relational Elaboration and Coherence (REC) Model. The Psychological Record, 60, 527-542. http://doi.org/10.1007/BF03395726

Barnes-Holmes, D., Murphy, A., Barnes-Holmes, Y., \& Stewart, I. (2010). The Implicit Relational Assessment Procedure: Exploring the impact of private versus public contexts and the response latency criterion on pro-white and anti-black stereotyping among white Irish individuals. The Psychological Record, 60(1), 57-79. https://doi. org/10.1007/BF03395694

Baruch, D. E., Kanter, J. W., Busch, A. M., Richardson, J. V., \& Barnes-Holmes, D. (2007). The differential effect of instructions on dysphoric and nondysphoric persons. The Psychological Record, 57, 543-555. https://doi. org/10.1007/BF03395594

Berg, E. A. (1948). A simple objective technique for measuring flexibility in thinking. The Journal of General Psychology, 39(1), 15-22. https://doi.or g/10.1080/00221309.1948.9918159

Berry, T. D., Geller, S. E., Calef, R. S., \& Calef, R. A. (1992). Moderating effects of social assistance on verbal interventions to promote 
safety belt use: An analysis of weak plys. Environment and Behavior, 24, 653-669. ttps:// doi.org/10.1177/0013916592245005

Biglan, A. (2015). The nurture effect: How the science of human behavior can improve our lives and our world. New Harbinger Publications.

Buhrman, M., Skoglund, A., Husell, J., Bergström, K., Gordh, T., Hursti, T., Bendelin, N., Furmark, T., \& Andersson, G. (2013). Guided internetdelivered acceptance and commitment therapy for chronic pain patients: A randomized controlled trial. Behaviour Research and Therapy, 51(6), 307-315. http://doi.org/10.1016/j. brat.2013.02.010

Bush, K. M., Sidman, M., \& de Rose, T. (1989). Contextual control of emergent equivalence relations. Journal of the Experimental Analysis of Behavior, 51, 29-45. https://doi.org/10.1901/ jeab.1989.51-29

Cassidy, S., Roche, B., Colbert, D., Stewart, I., \& Grey, I. M. (2016). A relational frame skills training intervention to increase general intelligence and scholastic aptitude. Learning and Individual Differences, 47, 222-235. https://doi. org/10.1016/j.lindif.2016.03.001

Catania, A. C., Shimoff, E., \& Matthews, B. A. (1989). An experimental analysis of rule governed behavior. In S. C. Hayes (Ed.), Rulegoverned behavior: Cognition, contingencies, and instructional control (pp. 119-150). New York: Plenum.

Colbert, D., Tyndall, I., Roche, B., \& Cassidy, S. (2018). Can SMART training really increase intelligence? A replication study. Journal of Behavioral Education, 27(4), 509-531. https:// doi.org/10.1007/s10864-018-9302-2

Cullen, C., Barnes-Holmes, D., Barnes-Holmes, Y., \& Stewart, I. (2009). The Implicit Relational Assessment Procedure (IRAP) and the malleability of ageist attitudes. The Psychological Record, 59(4), 591-620. https://doi.org/10.1007/ BF03395683

Cullinan, V. A., Barnes, D., \& Smeets, P. M. (1998). A precursor to the relational evaluation procedure: Analyzing stimulus equivalence. The Psychological Record, 48(1), 121-145. https:// doi.org/10.1007/BF03395262

Cullinan, V. A., Barnes-Holmes, D., \& Smeets, P.
M. (2000). A precursor to the relational evaluation procedure: Analyzing stimulus equivalence II. The Psychological Record, 50(3), 467-492. https://doi.org/10.1007/BF03395366

Cullinan, V. A., Barnes-Holmes, D., \& Smeets, P. M. (2001). A precursor to the relational evaluation procedure: Searching for the contextual cues that control equivalence responding. Journal of the Experimental Analysis of Behavior, 76(3), 339349. http://doi.org/ 10.1901/jeab.2001.76-339

Davlin, N. L., Rehfeldt, R. A., \& Lovett, S. (2011). A Relational Frame Theory approach to understanding perspective-taking using children's stories in typically developing children. European Journal of Behavior Analysis, 12(2), 403-430. http://doi.org/10.1080/15021149.201 1.11434392

De Houwer, J., \& Hughes, S. (2020). The psychology of learning: An introduction from a functional-cognitive perspective. Cambridge, MA: MIT Press

Devany, J. M., Hayes, S. C., \& Nelson, R. O. (1986). Equivalence class formation in language able and language-disabled children. Journal of Experimental Analysis of Behavior, 46, 243-257. https://doi.org/10.1901/jeab.1986.46-243

Dixon, M. R., Belisle, J., \& Stanley, C. R. (2018). Derived relational responding and intelligence: Assessing the relationship between the PEAK-E pre-assessment and IQ with individuals with autism and related disabilities. The Psychological Record, 68(4), 419-430. https:// doi.org/10.1007/s40732-018-0284-1

Dixon, M. R., Hayes, S. C., Stanley, C., Law, S., \& al-Nasser, T. (2020). Is Acceptance and Commitment Training or Therapy (ACT) a method that applied behavior analysts can and should use? The Psychological Record, 70, 559579. https://doi.org/10.1007/s40732-02000436-9

Donadeli, J. M., \& Strapasson, B. A. (2015). Effects of monitoring and social reprimands on instruction-following in undergraduate students. The Psychological Record, 65, 177-188. http:// doi.org/10.1007/s40732-014-0099-7

Drake, C. E., Kellum, K. K., Wilson, K. G., Luoma, J. B., Weinstein, J. H., \& Adams, C. H. (2010). Examining the Implicit Relational Assessment 
Procedure: Four pilot studies. The Psychological Record, 60, 81-100. https://doi.org/10.1007/ BF03395695

Dymond, S., \& Barnes-Holmes, D. (1998). The effects of prior equivalence testing and detailed verbal instructions on derived self-discrimination transfer: A follow-up study. The Psychological Record, 48, 147-170. https://doi. org/10.1007/BF03395263

Dymond, S., May, R. J., Munnelly, A., \& Hoon, A. E. (2010). Evaluating the evidence base for Relational Frame Theory: A citation analysis. The Behavior Analyst, 33(1), 97-117. https:// psycnet.apa.org/doi/10.1007/BF03392206

Dymond, S., Cella, M., Cooper, A., \& Turnbull, O. H. (2010). The contingency-shifting variant Iowa Gambling Task: An investigation with young adults. Journal of Clinical and Experimental Neuropsychology, 32, 239-248. https://doi.org/10.1080/13803390902971115

Eifert, G. H., Forsyth, J. P., Arch, J., Espejo, E., Keller, M., \& Langer, D. (2009). Acceptance and Commitment Therapy for anxiety disorders: Three case studies exemplifying a unified treatment protocol. Cognitive and Behavioral Practice, 16(4), 368-385. https://doi. org/10.1016/j.cbpra.2009.06.001

Folke, F., Parling, T., \& Melin, L. (2012). Acceptance and Commitment Therapy for depression: A preliminary randomized clinical trial for unemployed on long-term sick leave. Cognitive and Behavioral Practice, 19(4), 583-594. https://doi. org/10.1016/j.cbpra.2012.01.002

Foody, M., Barnes-Holmes, Y., Barnes-Holmes, D., Törneke, N., Luciano, C., Stewart, I., \& McEnteggart, C. (2014). RFT for clinical use: The example of metaphor. Journal of Contextual Behavioral Science, 3(4), 305-313. https://doi. org/10.1016/j.jcbs.2014.08.001

Forman, E. M., Herbert, J. D., Moitra, E., Yeomans, P. D., \& Geller, P. A. (2007). A randomized controlled effectiveness trial of Acceptance and Commitment Therapy and Cognitive Therapy for anxiety and depression. Behavior Modification, 31(6), 772-799. https://doi. org/10.1177/0145445507302202

Forman, E. M., Shaw, J. A., Goetter, E. M., Herbert, J. D., Park, J. A., \& Yuen, E. K. (2012). Long- term follow-up of a randomized controlled trial comparing Acceptance and Commitment Therapy and Standard Cognitive Behavior Therapy for anxiety and depression. Behavior Therapy, 43(4), 801-811. http://doi.org/ 10.1016/j.beth.2012.04.004

Gewirtz, J. L., \& Stingle, K. G. (1968). Learning of generalized imitation as the basis for identification. Psychological Review, 75, 374-397. https:// doi.org/10.1037/h0026378

Gore, N. J., Barnes-Holmes, Y., \& Murphy, G. (2010). The relationship between intellectual functioning and relational perspective-taking. International Journal of Psychology and Psychological Therapy, 10(1), 1-17.

Gorham, M., Barnes-Holmes, Y., Barnes-Holmes, D., \& Berens, N. (2009). Derived comparative and transitive relations in young children with and without autism. The Psychological Record, 59(2), 221-246. https://doi.org/10.1007/ BF03395660

Gross, A. C., \& Fox, E. J. (2009). Relational Frame Theory: An overview of the controversy. The Analysis of Verbal Behavior, 25(1), 87-98. https://doi.org/10.1007/BF03393073

Harte, C., Barnes-Holmes, D., Barnes-Holmes, Y., \& McEnteggart, C. (2018). The impact of high versus low levels of derivation for mutually and combinatorially entailed relations on persistent rule-following. Behavioural Processes, 157(August), 36-46. https://doi.org/10.1016/j. beproc.2018.08.005

Harte, C., Barnes-Holmes, D., Barnes-Holmes, Y., McEnteggart, C., Gys, J., \& Hasler, C. (2020). Exploring the potential impact of relational coherence on persistent rule-following: The first study. Learning \& Behavior, 48, 373-391. https://doi.org/10.3758/s13420-019-00399-0

Hayes, S. C. (1984). Making sense of spirituality. Behaviorism, 12(2), 99-110.

Hayes, S. C. (1986). The case of the silent dogVerbal reports and the analysis of rules: A review of Ericsson and Simon's Protocol Analysis: Verbal Reports as Data. Journal of the Experimental Analysis of Behavior, 45(3), 351363. http://doi.org/10.1901/jeab.1986.45-351

Hayes, S., \& Barnes, D. (1997). Analyzing derived stimulus relations requires more than 
the concept of stimulus class. Journal of the Experimental Analysis of Behavior, 68(2), 235244. https://doi.org/10.1901/jeab.1997.68235Hayes, L. J., Thompson, S., \& Hayes, S. C. (1989). Stimulus equivalence and rule following. Journal of the Experimental Analysis of Behavior, 52(3), 275-291. https://doi. org/10.1901/jeab.1989.52-275

Hayes, S. C., Barnes-Holmes, D., \& Roche, B. (Eds.). (2001). Relational frame theory: A post Skinnerian account of human language and cognition. New York: Plenum Press.

Hayes, S. C., \& Brownstein, A. J. (1986). Mentalism, behavior-behavior relations, and a behavioranalytic view of the purposes of science. The Behavior Analyst, 9(2), 175-190. https://doi. org/10.1007/BF03391944

Hayes, S. C., Brownstein, A. J., Devany, J. M., Kohlenberg, B. S., \& Shelby, J. (1987). Stimulus equivalence and the symbolic control of behavior. Mexican Journal of Behavior Analysis, 13, 361-374. http://doi.org/10.5514/rmac.v13. i3. 25325

Hayes, S. C., Brownstein, A. J., Haas, J. R., \& Greenway, D. E. (1986). Instructions, multiple schedules, and extinction: Distinguishing rule-governed from schedule-controlled behavior. Journal of the Experimental Analysis of Behavior, 46(2), 137-147. https://doi. org/10.1901/jeab.1986.46-137

Hayes, S. C., Brownstein, A. J., Zettle, R. D., Rosenfarb, I., \& Korn, Z. (1986). Rulegoverned behavior and sensitivity to changing consequences of responding. Journal of the Experimental Analysis of Behavior, 45(3), 237256. https://doi.org/10.1901/jeab.1986.45-237

Hayes, S.C, Fox, E., Gifford, E. V., Wilson, K. G., Barnes-Holmes, D., \& Healy. O. (2001). Derived relational responding as learned behavior. In S. C. Hayes, D. Barnes-Holmes, \& B. Roche (Eds). Relational frame theory: A post-skinnerian account of human language and cognition (pp. 21-49). New York: Kluwer Academic/Plenum Publishers

Hayes, S. C., \& Hayes, L. J. (1989). The verbal action of the listener as a basis for rule governance. In S. C. Hayes (Ed.), Rule-governed behavior: Cognition, contingencies, and instructional con- trol (pp. 153-190). New York: Plenum Press.

Hayes, S. C., Kohlenberg, B. S., \& Hayes, L. J. (1991). The transfer of specific and general consequential functions through simple and conditional equivalence relations. Journal of the Experimental Analysis of Behavior, 56, 119-137. https://doi.org/10.1901/jeab.1991.56-119

Hayes, S. C., Law, S., Malady, M., Zhu, Z., \& Bai, X. (2020). The centrality of sense of self in psychological flexibility processes: What the neurobiological and psychological correlates of psychedelics suggest. Journal of Contextual Behavioral Science, 15, 30-38. http://doi.org/ 10.1016/j. jcbs.2019.11.005

Hayes, J., Stewart, I., \& McElwee, J. (2016). Assessing and training young children in same and different relations using the relational evaluation procedure (REP). The Psychological Record, 66, 547-561. https://doi.org/10.1007/ s40732-016-0191-2

Hayes, J., Stewart, I., \& McElwee, J. (2017). Children's answering of yes-no questions: A review of research including particular consideration of the relational evaluation procedure. Behavioral Development Bulletin, 22(1), 173182. http://doi.org/10.1037/bdb0000027

Hayes, S. C., Strosahl, K. D., \& Wilson, K. G. (2012). Acceptance and commitment therapy: The process and practice of mindful change (2nd ed.). New York, NY: Guilford Press.

Hayes, L. J., Tilley, K. J., \& Hayes, S. C. (1988). Extending equivalence class membership to gustatory stimuli. The Psychological Record, 38(4), 473-482. http://doi.org/10.1007/ BF03395040

Henley, A. J., Hirst, J. M., Reed, F. D. D., Becirevic, A., \& Reed, D. D. (2017). Function altering effects of rule phrasing in the modulation of instructional control. The Analysis of Verbal Behavior, 33, 24-40. http://doi.org/10.1007/ s40616-016-0063-5

Hofmann, S. G., \& Hayes, S. C. (2020). Beyond the DSM: A process-based approach. Oakland, CA: Context Press / New Harbinger Publications.

Hojo, R. (2002). Effects of instructional accuracy on a conditional discrimination task. The Psychological Record, 52, 493-506. https://doi. org/10.1007/BF03395200 
Hughes, S., \& Barnes-Holmes, D. (2011). On the formation and persistence of implicit attitudes: New evidence from the implicit relational assessment procedure (IRAP). The Psychological Record, 61(3), 391-410. https://doi.org/10.1007/ BF03395768

Hughes, S. J., \& Barnes-Holmes, D. (2013). A Functional Approach to the Study of Implicit Cognition: The IRAP and the REC model. In B. Roche \& S. Dymond. (Eds.). Advances in relational frame theory \& contextual behavioural science: Research \& applications (pp. 97-126). Context Press.

Hunt, E. (2014). Teaching intelligence: Why, why it is hard and perhaps how to do it. Intelligence, 42(1), 156-165. https://doi.org/10.1016/j.intell.2013.06.018

Jackson, M. L., Larry Williams, W., Hayes, S. C., Humphreys, T., Gauthier, B., \& Westwood, R. (2016). Whatever gets your heart pumping: the impact of implicitly selected reinforcer-focused statements on exercise intensity. Journal of Contextual Behavioral Science, 5(1), 48-57. https://doi.org/10.1016/j.jcbs.2015.11.002

Jolliffe, T., \& Baron-Cohen, S. (1999). The strange stories test: A replication with high functioning adults with autism or Asperger syndrome. Journal of Autism and Developmental Disorders, 29(5), 395-406. http://doi.org/ 10.1023/a:1023082928366

Ju, W. C., \& Hayes, S. C. (2008). Verbal establishing stimuli: Testing the motivative effect of stimuli in a derived relation with consequences. The Psychological Record, 58(3), 339-363. https:// doi.org/10.1007/BF03395623

Kaland, N., Smith, L., \& Mortensen, E. L. (2008). Brief report: Cognitive flexibility and focused attention in children and adolescents with Asperger syndrome or high-functioning autism as measured on the computerized version of the Wisconsin card sorting test. Journal of Autism and Developmental Disorders, 38(6), 1161-1165. http://doi.org/10.1007/s10803-007-0474-1

Kantor, J. R. (1963). The scientific evolution of psychology. Principia Press.

Kemani, M. K., Hesser, H., Olsson, G. L., Lekander, M., \& Wicksell, R. K. (2016). Processes of change in Acceptance and Commitment
Therapy and Applied Relaxation for longstanding pain. European Journal of Pain, 20(4), 521-531. http://doi.org/ 10.1002/ejp.754

Kissi, A., Hughes, S., Mertens, G., Barnes-Holmes, D., DeHouwer, J., \& Crombez, G. (2017). A systematic review of pliance, tracking, and augmenting. Behavior Modification, 41(5), 683-707. http://doi.org/10.1177/0145445517693811.

Kohlenberg, B. S., Hayes, S. C., \& Hayes, L. J. (1991). The transfer of contextual control over equivalence classes through equivalence classes: a possible model for social stereotyping. Journal of the Experimental Analysis of Behavior, 56(3), 505518. https://doi.org/10.1901/jeab.1991.56-505

Kroger-Costa, A., \& Abreu-Rodrigues, J. (2012). Effects of historical and social variables on instruction following. The Psychological Record, 62(4), 691-706. https://doi.org/10.1007/ BF03395829

Law, S., \& Hayes, S. C. (2020). Murray Sidman: Fostering progress through foundational choices. Journal of the Experimental Analysis of Behavior, 115(1), 21-30. https://doi. org/10.1002/jeab.640

Levin, M., Hayes, S. C., \& Waltz, T. (2010). Creating an implicit measure of cognition more suited to applied research: A test of the Mixed Trial - Implicit Relational Assessment Procedure (MT-IRAP). International Journal of Behavioral Consultation and Therapy, 6, 245-262. http:// doi.org/10.1037/h0100911

Lipkens, R., Hayes, S. C., \& Hayes, L. J. (1993). Longitudinal study of the development of derived relations in an infant. Journal of Experimental Child Psychology, 56(2), 201-239. https://doi.org/10.1006/jecp.1993.1032

Lipkens, R., \& Hayes, S. C. (2009). Producing and recognizing analogical relations. Journal of the Experimental Analysis of Behavior, 91(1), 105126. http://doi.org/ 10.1901/jeab.2009.91-105

Lovett, S. (2012). An evaluation of multiple exemplar instruction to teach perspective-taking skills to young adults with autism: Deictic framing and cognitive defusion. In Dissertation Abstracts International: Section B: The Sciences and Engineering (Vol. 74, Issue 3-B(E)).

Luciano, C., Becerra, I. G., \& Valverde, M. R. (2007). The role of multiple-exemplar training 
and naming in establishing derived equivalence in an infant. Journal of the Experimental Analysis of Behavior, 87(3), 349-365. http://doi. org/ 10.1901/jeab.2007.08-06

Mackay, H. A., \& Sidman, M. (1984). Teaching new behavior via equivalence relations. In $\mathrm{P}$. H. Brooks, R. Sperber, \& C. MacCauley (Eds.), Learning and cognition in the mentally retarded (pp. 493-513). Hillsdale, NJ: Erlbaum

Martinez-Sanchez, H., \& Ribes-Inesta, E. (1996). Interactions of contingencies and instructional history on conditional discrimination. The Psychological Record, 46(2), 301-318.

McAuliffe, D., Hughes, S., \& Barnes-Holmes, D. (2014). The dark-side of rule governed behavior: An experimental analysis of problematic rule-following in an adolescent population with depressive symptomatology. Behavior Modification, 38(4), 587-613. http://doi. org/10.1177/0145445514521630

McHugh, L., Barnes-Holmes, Y., \& Barnes-Holmes, D. (2004a). Perspective-taking as relational responding: A developmental profile. The Psychological Record, 54(1), 115-144. https:// doi.org/10.1007/BF03395465

McHugh, L., Barnes-Holmes, Y., \& Barnes-Holmes, D. (2004b). A relational frame account of the development of complex cognitive phenomena: Perspective-taking, false belief understanding, and deception. International Journal of Psychology and Psychological Therapy, 4, 303-324.

McHugh, L., Barnes-Holmes, Y., \& BarnesHolmes, D. (2009). Understanding and training perspective-taking as relational responding. In R. A. Rehfeldt, Y. Barnes-Holmes, \& S. C. Hayes (Eds.), Derived relational responding. Applications for learners with autism and other developmental disabilities. New Harbinger Publication.

McLoughlin, S., \& Stewart, I. (2017). Empirical advances in studying relational networks. Journal of Contextual Behavioral Science, 6(3), 329-342. http://doi.org/10.1016/j.jcbs.2016.11.009

McLoughlin, S., Tyndall, I., \& Pereira, A. (2020). Convergence of multiple fields on a relational reasoning approach to cognition. Intelligence, 83, 101491. https://doi.org/10.1016/j.intell.2020.101491
Miller, J. R., Hirst, J. M., Kaplan, B. A., DiGennaro, F. D., \& Reed, D. D. (2014). Effects of mands on instructional control: A laboratory simulation. The Analysis of Verbal Behavior, 30(2), 100-112. http://doi.org/10.1007/s40616-014-0015-x

Montoya-Rodríguez, M. M., \& Molina-Cobos, F. J. M. (2016). Relationship between deictic relational responding and theory of mind tasks in children: A pilot study. The Psychological Record, 66(4), 573-587. https://doi.org/10.1007/ s40732-016-0193-0

Montoya-Rodríguez, M. M., \& Molina-Cobos, F. J. (2019). Training perspective taking skills in individuals with intellectual disabilities: A functional approach. Journal of Contextual Behavioral Science, 14, 1-10. https://doi. org/10.1016/j.jcbs.2019.08.003

Montoya-Rodríguez, M. M., McHugh, L., \& Molina-Cobos, F. M. (2017). Teaching perspective-taking skills to an adult with Down syndrome: A case study. Journal of Contextual Behavioral Science, 6(3), 293-297. http://doi. org/10.1016/j.jcbs.2017.04.012

Montoya-Rodríguez, M. M., Molina-Cobos, F., \& McHugh, L. (2017). Teaching perspective taking skills to an adult with Down syndrome: A case study": Corrigendum. Journal of Contextual Behavior Science, 6(4), 433. https:// doi.org/10.1016/j.jcbs.2017.09.003

Moran, O., \& McHugh, L. (2019). Patterns of relational responding and a healthy self in older adolescents. Journal of Contextual Behavioral Science, 12, 74-80. https://doi.org/10.1016/j. jcbs.2019.02.002

Murphy, C., \& Barnes-Holmes, D. (2010). Establishing complex derived manding with children with and without a diagnosis of autism. The Psychological Record, 60(3), 489-503. https://doi.org/10.1007/BF03395723

Murphy, C., Barnes-Holmes, D., \& Barnes-Holmes, Y. (2003). Manding and derived transformation of function in children with autistic spectrum disorder. Paper presented at the annual convention of The Association for Behavior Analysis, San Francisco, USA.

Neuringer, A. (1986). Can people behave "randomly?": The role of feedback. Journal of Experimental Psychology: General, 115(1), 62- 
75. https://doi.org/10.1037/0096-3445.115.1.62

O'Hora, D., Peláez, M., Barnes-Holmes, D., Rae, G., Robinson, K., \& Chaudhary, T. (2008). Temporal relations and intelligence: Correlating relational performance with performance on the WAIS-III. The Psychological Record, 58(4), 569-584. https://doi.org/10.1007/BF03395638

O’Reilly, A., Roche, B., Ruiz, M., Tyndall, I., \& Gavin, A. (2012). The Function Acquisition Speed Test (FAST): A behavior analytic implicit test for assessing stimulus relations. Psychological Record, 62, 507-528. http:// doi.org/10.1007/BF03395817

Perez, W. F., Kovac, R., de Almeida, J. H., \& de Rose, J. C. (in press). Teoria das Molduras Relacionais (RFT): conceitos, pesquisa e aplicação [Relational Frame Theory (RFT): Concepts, Research, and Application]. Editora Paradigma.

Power, P., Barnes-Holmes, D., Barnes-Holmes, Y., \& Stewart, I. (2009). The Implicit Relational Assessment Procedure (IRAP) as a measure of implicit relative preferences: A first study. The Psychological Record, 59(4), 621-640. https:// doi.org/10.1007/BF03395684

Persicke, A., Tarbox, J., Ranick, J., \& st. Clair, M. (2013). Teaching children with autism to detect and respond to sarcasm. Research in Autism Spectrum Disorders, 7(1), 193-198. https://doi. org/10.1016/j.rasd.2012.08.005

Pryor, K. W., Haag, R., \& O’Reilly, J. (1969). The creative porpoise: training for novel behavior. Journal of the Experimental Analysis of Behavior, 12(4), 653-661. http://doi.org/ 10.1901/jeab.1969.12-653

Quinones, J. L., \& Hayes, S. C. (2014). Relational coherence in ambiguous and unambiguous relational networks. Journal of the Experimental Analysis of Behavior, 101(1), 76-93. http://doi. org/ 10.1002/jeab.67

Rafacz, S. D., Houmanfar, R. A., Smith, G. S., \& Levin, M. E. (2019). Assessing the effects of motivative augmentals, pay-for-performance, and implicit verbal responding on cooperation. Psychological Record, 69(1), 49-66. https://doi. org/10.1007/s40732-018-0324-x

Rehfeldt, R. A., \& Root, S. L. (2005). Establishing derived requesting skills in adults with severe developmental disabilities. Journal of Applied
Behavior Analysis, 38(1), 101-105. http://doi. org/10.1901/jaba.2005.106-03

Roche, B., Barnes-Holmes, Y., Barnes-Holmes, D., Stewart, I., \& O’Hora, D. (2002). Relational frame theory: A new paradigm for the analysis of social behavior. The Behavior Analyst, 25(1), 75-91. http://doi.org/ 10.1007/BF03392046

Roddy, S., Stewart, I., \& Barnes-Holmes, D. (2010). Anti-fat, pro-slim, or both? Using two reaction-time based measures to assess implicit attitudes to the slim and overweight. Journal of Health Psychology, 15(3), 416-425. http://doi. org/10.1177/1359105309350232

Sidman, M. (1971). Reading and auditory-visual equivalences. Journal of Speech and Hearing Research, 14, 5-13. https://doi.org/10.1044/ jshr.1401.05

Sidman, M. (1994). Equivalence relations and behavior: A research story. Boston: Authors Cooperative.

Sidman, M., \& Tailby, W. (1982). Conditional discrimination vs. matching to sample: an expansion of the testing paradigm. Journal of the Experimental Analysis of Behavior, 37(1), 5-22. https://doi.org/10.1901/jeab.1982.37-5

Sidman, M., Rauzin, R., Lazar, R., Cunningham, S., Tailby, W., \& Carrigan, P. (1982). A search for symmetry in the conditional discriminations of rhesus monkeys, baboons, and children. Journal of the Experimental Analysis of Behavior, 37(1), 23-44. https://doi.org/10.1901/jeab.1982.37-23

Sidman, M., Kirk, B., \& Willson-Morris, M. (1985). Six-member stimulus classes generated by conditional-discrimination procedures. Journal of the Experimental Analysis of Behavior, 43, 2142. https://doi.org/10.1901/jeab.1985.43-21

Sidman, M., Willson-Morris, M., \& Kirk, B. (1986). Matching-to-sample procedures and the development of equivalence relations: The role of naming. Analysis \& Intervention in Developmental Disabilities, 6(1-2), 1-19. https://doi.org/10.1016/0270-4684(86)90003-0 Sidman, M. (2000). Equivalence relations and the reinforcement contingency. Journal of the Experimental Analysis of Behavior, 74(1), 127146. https://doi.org/10.1901/jeab.2000.74-127

Skinner, B. F. (1957). Verbal Behavior. AppletonCentury-Crofts. 
Skinner, B. F. (1969). Contingencies of Reinforcement: A Theoretical Analysis. Appleton CenturyCrofts.

Skinner, B. F. (1971). Beyond freedom and dignity. New York: Knopf.

Skinner, B. F. (1976). About Behaviorism. Vintage Books.

Skinner, B. F. (1989). The behavior of the listener. In S. C. Hayes (Eds.), Rule-governed behavior: Cognition, contingencies and instructional control (pp. 85-96). New York: Plenum.

Smeets, P. M., Barnes-Holmes, D., \& Striefel, S. (2006). Establishing and reversing equivalence relations with a precursor to the relational evaluation procedure. The Psychological Record, 56(2), 267-286. https://doi.org/10.1007/ BF03395550

Smeets, P. M., Wijngaarden, M. v., Barnes-Holmes, D., \& Cullinan, V. (2004). Assessing stimulus equivalence with a precursor to the relational evaluation procedure. Behavioural Processes, 65(3), 241-251. http://doi.org/ 10.1016/j. beproc.2003.10.004.

Steele, D. L., \& Hayes, S. C. (1991). Stimulus equivalence and arbitrarily applicable relational responding. Journal of the Experimental Analysis of Behavior, 56, 519-555. https://doi. org/10.1901/jeab.1991.56-519

Stewart, I., Barnes-Holmes, D., \& Roche, B. (2004). A functional-analytic model of analogy using the relational evaluation procedure. The Psychological Record, 54(4), 531-552. https:// doi.org/10.1007/BF03395491

Stewart, I., Barnes-Holmes, D., Roche, B., \& Smeets, P. M. (2001). Generating derived relational networks via the abstraction of common physical properties: A possible model of analogical reasoning. The Psychological Record, 51(3), 381408. https://doi.org/10.1007/BF03395405

Stewart, I., Barnes-Holmes, D., Roche, B., \& Smeets, P. M. (2002). A functional-analytic model of analogy: A relational frame analysis. Journal of the Experimental Analysis of Behavior, 78(3), 375-396. http://doi. org/10.1901/jeab.2002.78-375.

Sullivan, E. V., McCullough, G., \& Stager, M. (1970). A developmental study of the relationship between conceptual, ego, and moral development. Child Development, 41(2), 399411. https://doi.org/10.2307/1127040

Tarbox, J., Zuckerman, C. K., Bishop, M. R., Olive, M. L., \& O'Hora, D. P. (2011). Rule governed behavior: Teaching a preliminary repertoire of rule-following to children with Autism. The Analysis of Verbal Behavior, 27(1), 125-139.

Turnbull, O. H., Evans, C. E. Y., Kemish, K., Park, S., \& Bowman, C. H. (2006). A novel set shifting modification of the Iowa gambling task: Flexible emotion-based learning in schizophrenia. Neuropsychology, 20(3), 290-298. https:// doi.org/10.1037/0894-4105.20.3.290

Twohig, M. P. (2009). Acceptance and Commitment Therapy for treatment-resistant Posttraumatic Stress Disorder: A case study. Cognitive and Behavioral Practice, 16(3), 243-252. https://doi. org/10.1016/j.cbpra.2008.10.002

Valdivia, S., Luciano, C., \& Molina, F. J. (2006). Verbal regulation of motivational states. The Psychological Record, 56(4), 577-595. http://doi. org/ 10.1007/BF03396035

Vizcaíno-Torres, R. M., Ruiz, F. J., Luciano, C., López-López, J. C., Barbero-Rubio, A., \& Gil, E. (2015). The effect of relational training on intelligence quotient: A case study. Psicothema, 27(2), 120-127. http://doi. org/10.7334/psicothema2014.149.

Walser, R. D., \& Westrup, D. (2007). Acceptance and Commitment Therapy for the Treatment of Post-Traumatic Stress Disorder and TraumaRelated Problems: A Practitioner's Guide to Using Mindfulness and Acceptance Strategies. New Harbinger Publications.

Weil, T. M., Hayes, S. C., \& Capurro, P. (2011). Establishing a deictic relational repertoire in young children. The Psychological Record, 61(3), 371-390. https://doi.org/10.1007/BF03395767

Weiss, A., \& Neuringer, A. (2012). Reinforced variability enhances object exploration in shy and bold rats. Physiology \& Behavior, 107(3), 451-457. https://doi.org/10.1016/j.physbeh.2012.07.012

Wellman, H. M., \& Lagattuta, K. H. (2004). Theory of mind for learning and teaching: The nature and role of explanation. Cognitive Development, 19(4), 479-497. https://doi.org/10.1016/j.cogdev.2004.09.003 
Wetherell, J. L., Afari, N., Rutledge, T., Sorrell, J. T., Stoddard, J. A., Petkus, A. J., Solomon, B. C., Lehman, D. H., Liu, L., Lang, A. J., \& Atkinson, H. J. (2011). A randomized, controlled trial of acceptance and commitment therapy and cognitive-behavioral therapy for chronic pain. Pain, 152(9), 2098-2107. http://doi.org/ 10.1016/j.pain.2011.05.016

Whelan, R., \& Barnes-Holmes, D. (2004). Empirical models of formative augmenting in accordance with the relations of same, opposite, morethan and less-than. International Journal of Psychology and Psychological Therapy, 4(2), 285-302.

Wilson, D. S. \& Hayes, S. C. (Eds.). (2018). Evolution and contextual behavioral science: An integrated framework for understanding, predicting, and influencing human behavior. Oakland, CA: Context Press / New Harbinger Publications.

Wulfert, E., \& Hayes, S. C. (1988). Transfer of a conditional ordering response through conditional equivalence classes. Journal of the Experimental Analysis of Behavior, 50(2), 125-144. https://doi. org/10.1901/jeab.1988.50-125

Zettle, R. D. (2015). Acceptance and Commitment Therapy for depression. Current Opinion in Psychology, 2, 65-69. https://doi.org/10.1016/j. copsyc.2014.11.011

Zettle, R. D., \& Hayes, S. C. (1982). Rule governed behavior: A potential theoretical framework for cognitive behavior therapy. In P. C. Kendall (Ed.), Advances in cognitivebehavioral research and therapy (pp. 73118). New York: Academic.

Zettle, R. D., \& Young, M. J. (1987). Rule-following and human operant responding: Conceptual and methodological considerations. The Analysis of Verbal Behavior, 5, 33-39. http://doi. org/ 10.1007/BF03392818
Informações do Artigo

Histórico do artigo:

Accepted in: 01/Feb/2021

Editor: William F. Perez 